\title{
Safety and Feasibility of Single Incision Laparoscopic Spleen Preserving Distal Pancreatectomy
}

\author{
Kee-Hwan Kim, M.D., Ph.D.
}

Division of Hepato-Pancreato-Biliary Surgery, Department of Surgery, Uijeongbu St.Mary's Hospital, College of Medicine, The Catholic University of Korea, Uijeongbu, Korea

\author{
Corresponding author \\ Kee-Hwan Kim \\ Division of Hepato-Pancreato-Biliary Surgery, Department of Surgery, Uijeongbu St.Mary's Hospital, College of Medicine, The Catholic University of \\ Korea, 271, Cheonbo-ro, Uijeongbu 11765, Korea \\ Tel: +82-31-847-2717, Fax: +82-31-820-3562, E-mail: keehwan@catholic.ac.kr
}

This is an Open Access article distributed under the terms of the Creative Commons Attribution Non-Commercial License (http:// creativecommons.org/licenses/by-nc/4.0/) which permits unrestricted non-commercial use, distribution, and reproduction in any medium, provided the original work is properly cited.

Copyright (๑) 2016 The Journal of Minimally Invasive Surgery. All rights reserved.
복강경 수술의 장비와 수술기구의 개발과 수술경험이 축적되 어 단일공 복강경수술까지 진행되어 로봇수술의 장점이 있지만 아직은 단일공 복강경수술은 숙련된 술자에 의해서 복강내 많 은 장기에서 진행되고 있으며 현재 경험이 많이 축적되어가고 있는 실정이다. 기존의 고식적 복강경수술에 비해 미용적인 효 과와 통증의 감소를 기대하여 췌장의 양성질환뿐만 아니라 숙 련된 술자에 의하여 경계성질환에서 악성질환에도 적용되어 진 행되고 있다. ${ }^{1-13}$ 대부분은 그 대상군이 20 명 이하의 환자를 대 상으로 연구를 진행하여 결론을 내리기엔 부족하며 기존의 복 강경수술에 뒤지지 않는 결과를 지향하고 있는 실정이다. ${ }^{13}$ 단 일공 복강경수술의 난점인 복강내외에서의 기구간의 충돌, 술자 와 카메라 조수와의 충돌, 견인의 어려움 그리고 Triangulation 의 소실을 극복하기 위한 다양한 기구의 사용과 적용을 통하여 단일복강경의 어려움을 극복하기 위한 노력을 하고 있다., ${ }^{3,614,15}$ 단일공 복강경하 원위췌장절제술에 대한 연구는 2010년부터 증 례로 보고 된 이후, ${ }^{1-4,7,12}$ 현재까지 고식적 복강경하 원위췌장절 제술과 단일공 복강경하 원위췌장절제술의 비교연구는 2 편 가 량의 후향적 연구가 있었으며, 10,13 전향적 연구는 한 편도 출간 되지 않았다. 고식적 복강경하 원위췌장절제술과 단일공 복강 경하 원위췌장절제술의 비교연구에서 탁월한 미용효과와 재원
기간의 감소를 보고하였고, 수술시간의 차이는 2편의 논문에서 서로 다른 결과를 보였고, 합병증에 대하여 통계적인 차이는 없 음을 보고하고 있다. ${ }^{10,13}$ 췌장절제술에 있어서 아킬레스건이라고 할 수 있는 수술 후 췌장루(Pancreatic fistula)가 주된 합병증이 다. ${ }^{16-19}$ 이런 이유로 수술 후 배액을 목적으로 배액관을 배꼽을 통해서 설치하기도 하지만 최단의 거리에 적절한 배액을 위하여 단일공 외에 추가로 1 개의 투관침을 삽입하여 수술중에 적절 한 견인과 복강내 봉합을 용이하게 시행한 경험을 보고 하였다. ${ }^{3}$ 로봇복강경 췌장절제술로 인한 혈관손상에 의한 개복전환 확 대수술 후 사망한 증례보고가 있는바, ${ }^{8}$ 경험이 많지 않은 술자 에 의해 수술이 시행될 경우 혈관손상 등의 심각한 합병증 발 생 가능성에 대해 술자의 학습곡선과 함께 비교, 분석하는 것 이 절대적으로 필요 할 것으로 생각된다. 췌장절제술후 복강내 배액관의 설치여부에 대한 대단위 무작위 비교연구에서 설치하 지 않았던 군에서 한사람에 생기는 합병증의 수가 증가하고 합 병증의 중증도가 증가하였고 위마비(gastroparesis), 복강내 농 양의 증가, 심한 설사, 수술후 경피적 배액술 필요, 재원기간의 연장 그리고 사망률이 $3 \%$ 에서 $12 \%$ 까지 증가하여 연구를 조기 에 중단하였다. ${ }^{20}$ 이에 반하여 수술후 배액관을 오래 둘수록 합 병증이 증가한다는 보고 ${ }^{21}$ 도 있기에 배액관의 제거 시기를 환자 
의 임상양상을 관찰하여 적절한 시기에 제거하는 것이 좋을 것 으로 보인다. 단일공 복강경하 췌장절제술후에 가장 문제가 될 수 있는 합병증으로 췌장루(Pancreatic fistula)로 수술후 배액관 을 설치하지 않았을 경우 수술 후 절제면에서의 췌장염의 진행 이 진행 될 경우 생기는 합병증으로 인하여 재원기간이 길어지 고 침습적인 배액술까지 필요할 경우 미용적인 효과와 통증 감 소 등의 잠재적인 긍정적인 효과가 모두 감소되는 부정적인 결 과를 초래할 수 있기에 수술의 안전성과 효율성을 고려하여 적 절한 수술의 적응증을 가지고 시행하여야 할 것이다. 또한 결론 에서 저자들이 기술한 개복전환의 경우가 많음에 유의하여 적 절한 수술 적응증을 선택하여 이 술식을 시행하는 것이 좋겠다. 수술 후 합병증의 정도가 다양한 췌장질환에서의 단일공 복강 경하 췌장절제술의 적용과 그 유효성에 대하여 연구를 진행하 여 유익한 정보를 주신 것에 대하여 저자들에게 감사를 드린다.

\section{REFERENCES}

1) Chang SK, Lomanto D, Mayasari M. Single-port laparoscopic spleen preserving distal pancreatectomy. Minim Invasive Surg 2012;2012:197429.

2) Haugvik SP, Rosok BI, Waage A, Mathisen O, Edwin B. Singleincision versus conventional laparoscopic distal pancreatectomy: a single-institution case-control study. Langenbecks Arch Surg 2013;398:1091-1096.

3) Kim EY, You YK, Kim DG, et al. Dual-incision laparoscopic spleen-preserving distal pancreatectomy. Ann Surg Treat Res 2015;88:174-177.

4) Kuroki T, Adachi T, Okamoto T, Kanematsu T. Single-incision laparoscopic distal pancreatectomy. Hepatogastroenterology 2011;58:1022-1024.

5) Kuroki T, Kitasato A, Adachi T, Soyama A, Takatsuki M, Eguchi S. Single-incision laparoscopic distal pancreatectomy: our initial experience. Hepatogastroenterology 2014;61:212-214.

6) Machado MA, Surjan RC, Makdissi FF. Laparoscopic Distal Pancreatectomy Using Single-Port Platform: Technique, Safety, and Feasibility in a Clinical Case Series. J Laparoendosc Adv Surg Tech A 2015;25:581-585.

7) Misawa T, Ito R, Futagawa $Y$, et al. Single-incision laparoscopic distal pancreatectomy with or without splenic preservation: how we do it. Asian J Endosc Surg 2012;5:195-199.

8) Ryan CE, Ross SB, Sukharamwala PB, Sadowitz BD, Wood TW, Rosemurgy AS. Distal pancreatectomy and splenectomy: a robotic or LESS approach. Jsls 2015;19:e2014.00246.
9) Srikanth G, Shetty N, Dubey D. Single incision laparoscopic distal pancreatectomy with splenectomy for neuroendocrine tumor of the tail of pancreas. J Minim Access Surg 2013;9:132-135.

10) Yao D, Wu S, Li Y, Chen Y, Yu X, Han J. Transumbilical singleincision laparoscopic distal pancreatectomy: preliminary experience and comparison to conventional multi-port laparoscopic surgery. BMC Surg 2014;14:105.

11) Yao D, Wu S, Tian Y, Fan Y, Kong J, Li Y. Transumbilical singleincision laparoscopic distal pancreatectomy: primary experience and review of the English literature. World J Surg 2014;38:11961204.

12) Barbaros U, Sumer A, Tunca F, et al. Our early experiences with single-incision laparoscopic surgery: the first 32 patients. Surg Laparosc Endosc Percutan Tech 2010;20:306-311.

13) Han HJ, Yoon SY, Song TJ, et al. Single-port laparoscopic distal pancreatectomy: initial experience. J Laparoendosc Adv Surg Tech A 2014;24:858-863.

14) Kim MJ, Kim TS, Kim KH, An CH, Kim JS. Safety and feasibility of needlescopic grasper-assisted single-incision laparoscopic cholecystectomy in patients with acute cholecystitis: comparison with three-port laparoscopic cholecystectomy. J Laparoendosc Adv Surg Tech A 2014;24:523-527.

15) Kim SJ, Kim $\mathrm{KH}$, An $\mathrm{CH}$, Kim JS. Innovative technique of needlescopic grasper-assisted single-incision laparoscopic common bile duct exploration: A comparative study. World J Gastroenterol 2015;21:12857-12864.

16) Adachi E, Harimoto N, Yamashita $Y$, et al. Pancreatic leakage test in pancreaticoduodenectomy: relation to degree of pancreatic fibrosis, pancreatic amylase level and pancreatic fistula. Fukuoka Igaku Zasshi 2013;104:490-498.

17) Addeo P, Delpero JR, Paye F, et al. Pancreatic fistula after a pancreaticoduodenectomy for ductal adenocarcinoma and its association with morbidity: a multicentre study of the French Surgical Association. HPB (Oxford) 2014;16:46-55.

18) Figueras J. Author's reply: Randomized clinical trial of pancreaticogastrostomy versus pancreaticojejunostomy on the rate and severity of pancreatic fistula after pancreaticoduodenectomy ( $\mathrm{Br} J$ Surg 2013;100:1597-1605). Br J Surg 2014;101:290.

19) Figueras J, Sabater L, Planellas $P$, et al. Randomized clinical trial of pancreaticogastrostomy versus pancreaticojejunostomy on the rate and severity of pancreatic fistula after pancreaticoduodenectomy. Br J Surg 2013;100:1597-1605.

20) Van Buren G, 2nd, Bloomston M, Hughes SJ, et al. A randomized 
prospective multicenter trial of pancreaticoduodenectomy with and without routine intraperitoneal drainage. Ann Surg 2014;259:605612.
21) Adham M, Chopin-Laly X, Lepilliez V, Gincul R, Valette PJ, Ponchon T. Pancreatic resection: drain or no drain? Surgery 2013;154:1069-1077. 